\title{
Desenvolvimento de material instrucional (folder) para Educação não formal da Paleontologia em um Museu de Ciências do Sul do Brasil
}

Everton Fernando Alves*, Vinícius Silva Guizellini**, Ana Paula Vidotti***

\section{Resumo}

O desenvolvimento de material instrucional impresso a ser disponibilizado no ambiente museológico não pode ser entendido fora do contexto da educação científica. Sendo assim, este estudo teve como objetivo descrever o processo de construção de um folder e suas principais características para a difusão do conhecimento paleontológico e ampliação do potencial de alfabetização científica do Museu Dinâmico Interdisciplinar da Universidade Estadual de Maringá (MUDI/UEM). Utilizou-se a pesquisa-ação como método de pesquisa, e essa foi desenvolvido em quatro etapas: escolha do conteúdo, com base nas necessidades do público-alvo; escolha de ilustrações; fotografias das principais amostras fósseis da coleção; e preparação do conteúdo, baseado na literatura científica. Acredita-se que, da forma como o folder foi desenvolvido, sua utilização como ferramenta de educação aumentará a conscientização acerca da importância da Paleontologia, sua ocorrência na região e o consequente geoturismo urbano.

Palavras-chave: Divulgação científica. Material didático. Recursos Educacionais.

* Especialista em Paleontologia e Cultura pela Faculdade Futura. Mediador do Setor de Paleontologia do Museu Dinâmico Interdisciplinar (MUDI/UEM). E-mail: evertonando@hotmail.com

** Mestrando em Biologia comparada pela UEM. Mediador do Setor de Paleontologia do MUDI/UEM. E-mail: viniciusguizellini@gmail.com

*** Doutora em Anatomia dos Animais Domésticos e Silvestres pela USP. Coordenadora do MUDI/UEM. E-mail: apvidotti@uem.br 


\section{Introdução}

O ensino promovido no ambiente escolar nem sempre permite aos estudantes assimilarem efetivamente conhecimentos científicos, pois grande parte desse tipo de saber é rapidamente esquecida pela forma como o método de ensino é aplicado (PEDRANCINI et al., 2007). Nesse sentido, têm sido propostas alternativas para o ensino-aprendizagem da Paleontologia, tais como o uso de vários recursos que possibilitam uma melhor compreensão e um ambiente mais favorável ao aprendizado (BERGQVIST e PRESTES, 2014).

Visita a museus tem sido um desses recursos cada vez mais comum e eficiente para a diversificação no processo metodológico de ensino e para a promoção mais eficaz da aprendizagem. Os museus que possuem exposições voltadas ao ensino da Paleontologia, por exemplo, se enquadram em um modelo de educação socioconstrutivista. No qual o conhecimento é desenvolvido por meio da interação e ações mútuas entre os indivíduos e o meio. Porém, este modelo, embora ideal também enfrenta desafios e a principal dificuldade consiste na interação entre os visitantes e o museu, de modo que possibilite não só uma alfabetização científica, mas a expansão de novos conteúdos (VERONESE, 2011).

O Museu Dinâmico Interdisciplinar (MUDI) da Universidade Estadual de Maringá (UEM) é hoje o segundo maior museu de ciências da região Sul do Brasil e o maior do estado do Paraná. O MUDI possui uma exposição paleontológica chamada: "O passado e o presente da Biodiversidade" que recebe uma média semanal de visitação de 800 pessoas entre crianças, jovens e adultos. Contém uma linha de tempo com um grande painel abordando representações dos períodos geológicos componentes das Eras Paleozóica, Mesozóica e Cenozóica, acompanhados de espécimes fósseis originais e réplicas representativas da vida pretérita marinha e terrestre de várias regiões do Brasil para seu uso didático compõem esta exposição.

Apesar desta gama de informações e objetos apresentados neste espaço, durante as visitas, ao longo do tempo, constatou-se a necessidade de conteúdos adicionais de divulgação do setor de Paleontologia a ser disponibilizado ao público. Como um folder explicativo impresso que contemplasse um mini-catálogo do acervo, contendo informações sobre os espécimes apresentados na exposição e sobre relevantes instruções básicas de Paleontologia, bem como a importância da nossa região em termos de descobertas científicas para a área. Este processo torna-se relevante, uma vez que com as informações úteis no folder, pode-se incentivar o leitor a guardar o 
folheto ou até mesmo passá-lo para outras pessoas, servindo assim como uma fonte de informação e conhecimento.

Pesquisas em Educação têm associado o folder como importante estratégia de baixo custo no processo de ensino-aprendizagem, uma vez que é portador de valores, pode ser utilizado em diversas atividades sociocomunicativas e no estabelecimento de habilidades de leitura e senso crítico no leitor (RODRIGUES, 2014). Além do que, os elementos verbais e não verbais, que compõem um folder, são permeados de estratégias de persuasão, que na maioria das vezes, passam despercebidas pelo leitor (DE PAULA e CARVALHO, 2014; RODRIGUES, 2014). Ademais, para Karwoski (2005), todo folder é produzido contextualmente, com intuito discursivo e finalidades específicas.

É neste sentido que o desenvolvimento de material instrucional no formato folder se torna justificável devido à função que este pode exercer como ferramenta de apoio no processo educativo durante as visitas guiadas ao museu, além da possibilidade de distribuí-lo em hotéis, restaurantes e pontos turísticos da cidade, acrescentando maior valor informativo e cultural para o espaço do MUDI.

Diante disso, este estudo teve como objetivo descrever o processo de construção de um folder e suas principais características para a difusão do conhecimento paleontológico e ampliação do potencial de alfabetização científica do MUDI.

\section{A alfabetização científica em museus}

Atualmente, a geração millenials, isto é, a geração de estudantes nascida entre 1980 e 2000, e a geração Z, ou simplesmente pós-millennials, que surgiu entre 2001 e 2010, além da geração alpha, a partir de 2010, são reconhecidas como as primeiras a vivenciar com profundidade experiências digitais desde o seu nascimento (INDALÉCIO e RIBEIRO, 2016). Para essas gerações, existe um fosso comunicacional que se instala entre as escolas e os alunos no que diz respeito ao antigo formato de ensino de ciências, ainda em voga, estabelecido no local físico da sala de aula e com a utilização de textos cansativos e de difícil compreensão.

Desenvolver atividades que venham a dinamizar a forma de ensino de ciências, em especial da Paleontologia, entre alunos e professores, é a palavra-chave no processo pedagógico de ensino desses conteúdos. O saber paleontológico tem atual importância para a compreensão do mundo a nossa volta, frente às transformações que o planeta enfrentou e pode vir a sofrer futuramente. É neste contexto que en- 
tram os setores da Paleontologia em museus de ciências. Como um recurso eficaz a favor da popularização do conhecimento científico, os museus têm utilizado de forma prática, aplicada e criativa maneiras de facilitar o acesso à informação para o seu público (LEAL, 2011). Observa-se que essa é exatamente a necessidade das novas gerações que buscam novidades, criatividade e autenticidade nas exposições com as quais possam interagir e se emocionar (CADAVEZ, 2017).

Por outro lado, muitos museus brasileiros de História Natural ainda se mantêm bastante antiquados e não têm conseguido acompanhar as mudanças vindas do mundo digital, seja devido às dificuldades econômicas ou simplesmente por ignorar as dinâmicas educacionais em ciências, fazendo com que a sua eficácia como recurso de disseminação (e consequente educação) científica possa ser questionada (KELLNER, 2005; VIEIRA et al., 2007). Uma vez que tais museus não conseguem acompanhar as novas concepções museológicas e as novas práticas de circulação livre de informações científicas, resulta em um distanciamento entre museu e sociedade. No entanto, o surgimento de novos movimentos e conceitos no campo da museologia a partir do novo milênio tem modificado e ampliado a atuação dos museus (VIEIRA et al., 2007).

Existem atualmente, por exemplo, museus brasileiros que, além de exercer funções de preservar e expor os fósseis encontrados na região também se encarregam de estimular a economia local através do crescente turismo paleontológico, com o auxílio de informações úteis, por meio de estratégias de marketing, as quais atraem instituições e estabelecimentos públicos e privados. Ademais, esse "geoturismo paleontológico" regional carrega consigo o compromisso de conscientizar a comunidade para a incorporação de novos hábitos, desenvolvendo consciência e responsabilidade, acerca da importância da não degradação do ambiente natural e social (SANTOS, CARVALHO e RIBEIRO, 2006).

Pesquisas têm demonstrado que discutir e incentivar novas abordagens educacionais devem ser prioridades dos museus, considerados "museus fórum", caracterizados como locais de debate, úteis no pensar e realizar múltiplas estratégias pedagógicas a fim de encontrar maneiras eficazes de comunicação para a educação paleontológica de qualidade para as futuras gerações (VIEIRA et al., 2007).

Portanto, há maneiras de atrair e fidelizar millenials e pós-millenials, com foco no aumento de recursos visuais de baixo custo, em consonância com a realidade e expectativa dessa nova geração de estudantes, de maneira interativa e contextualizada, em uma parceria entre a escola (educação formal) e o museu (educação não formal) (LEAL, 2011). Uma dessas possibilidades de se promover a popularização 
do conhecimento paleontológico é justamente a utilização de folders como recurso midiático importante para tornar a exposição muito mais interessante e significativa, e de igual modo como prática social importante na conscientização de estudantes e comunidade com relação à preservação do meio ambiente natural.

\section{Elaboração do Folder}

O método da pesquisa-ação foi utilizado durante o processo de desenvolvimento do folder. É uma metodologia muito utilizada em projetos de pesquisa educacional, uma vez que permite com que pesquisadores em educação produzam informações e conhecimentos de uso mais efetivo, inclusive ao nível pedagógico, possibilitando condições para ações e transformações de situações dentro de qualquer ambiente educativo. O principal pressuposto desse método é a construção do conhecimento de maneira coletiva e participativa, buscando identificar soluções para um problema que necessita ser estudado, no caso, o conteúdo científico relacionado à Paleontologia (THIOLLENT, 2005).

Com base nisso, o folder foi desenvolvido em quatro etapas: 1) escolha do conteúdo pelos próprios mediadores do setor de Paleontologia do MUDI; 2) escolha de ilustrações; 3) fotografias das principais amostras fósseis da coleção museológica; e 4) preparação do conteúdo, baseado na literatura científica.

Na primeira fase, inicialmente buscou-se um aprofundamento do assunto e uma fundamentação teórica a fim de reunir o conteúdo base do material instrucional. Em seguida, organizaram-se as informações, selecionando as mais relevantes de acordo com os dados do perfil do público-alvo. Logo depois, o conteúdo foi preparado com textos breves em linguagem acessível acerca de conceitos e definição de Paleontologia, processo de formação dos fósseis e importância de museus voltados à disseminação do conhecimento científico, em especial da Paleontologia. Também foram inseridos breves conteúdos sobre os fósseis encontrados nesta região de influência do museu e as subsequentes publicações científicas e, especialmente, o diferencial da exposição paleontológica do MUDI.

Neste trabalho, a produção do folder deu-se como uma atividade colaborativa, sendo desenvolvido tanto por professor quanto alunos, através de estudos teóricos, seguido de revisões, acréscimos e ajustes até que o material estivesse pronto para a finalização gráfica. 
Para esta última fase de diagramação, o modelo de folder aqui proposto é dividido em duas dobras, formatado para folha A4, orientação horizontal. Sua face interna é composta de três seguimentos que apresentam figuras e textos sobre fósseis de invertebrados e vertebrados marinhos (Figuras 1), com destaque a uma réplica fóssil que tem especial importância para a Paleontologia: o réptil marinho Stereosternum tumidum - um mesossaurídeo do início do Permiano do Brasil e também da Grande Bacia Karoo da África do Sul, o que comprova que no passado esses continentes estiveram unidos e foram separados pela deriva continental (OELOFSEN e ARAÚJO, 1987).

Figura 1: Invertebrados e vertebrados marinhos: (a) corais e duas classes de moluscos da Era Paleozóica: gastrópodes e bivalves; (b) cefalópodes; (c) Trilobitas, artrópodes do Paleozóico; (d) peixes da chapada do Araripe; (e) Stereosternum tumidum, réptil marinho mesossaurídeo proveniente da Formação Irati, Bacia do Paraná
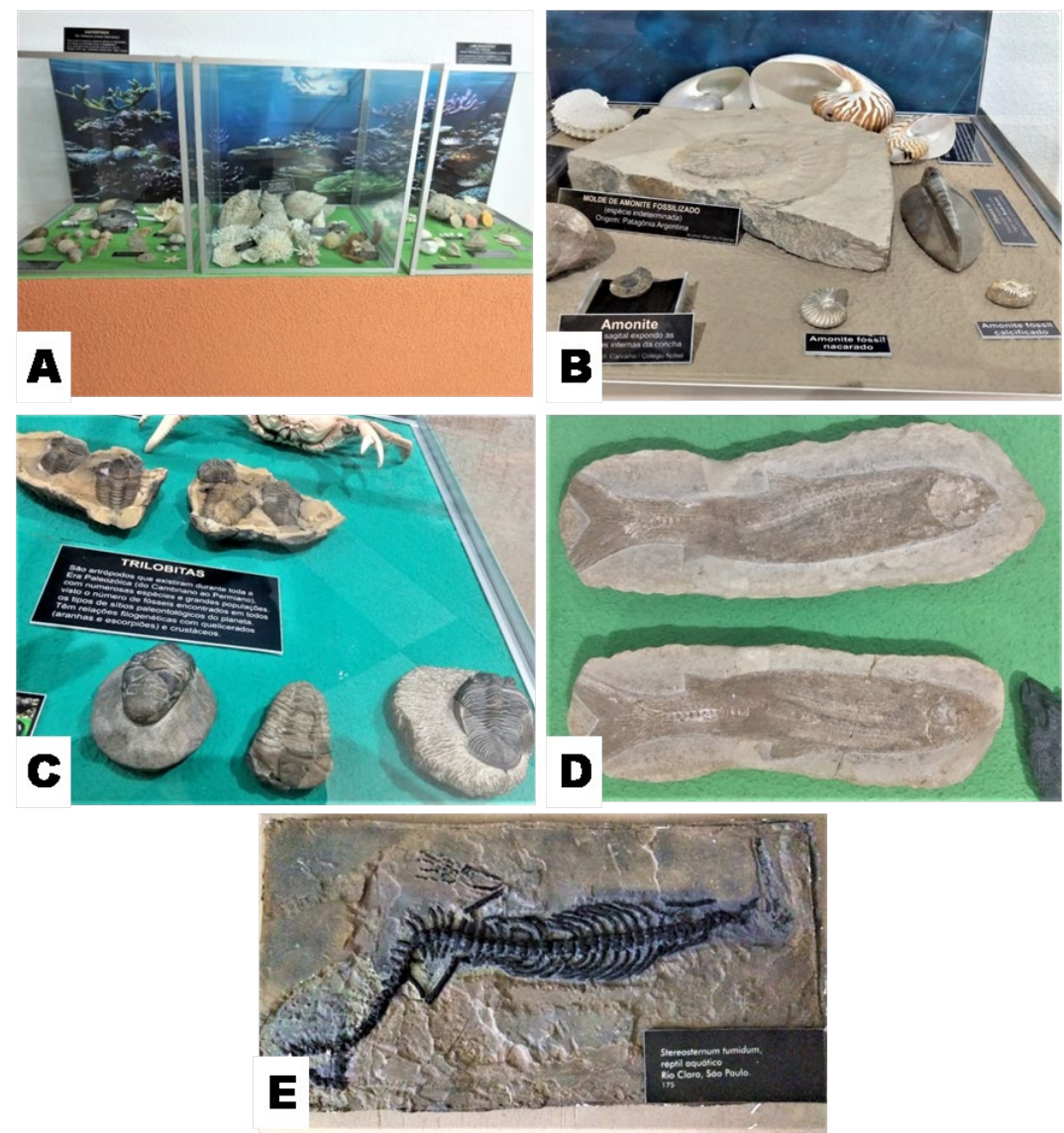

Fonte: Autores (2019). 
Exemplares de fósseis representantes da vida vegetal pretérita (Figura 2), que também compõem as imagens da face interna do folder, se constituem em um grupo de vegetais de 260 milhões de anos atrás (Período Permiano). Isto é, amostras que datam de antes da chegada dos dinossauros no planeta Terra.

Figura 2: Amostras de Pteridófitas e outros tipos de madeiras petrificadas, estróbilos de gimnospermas e raízes tuberosas

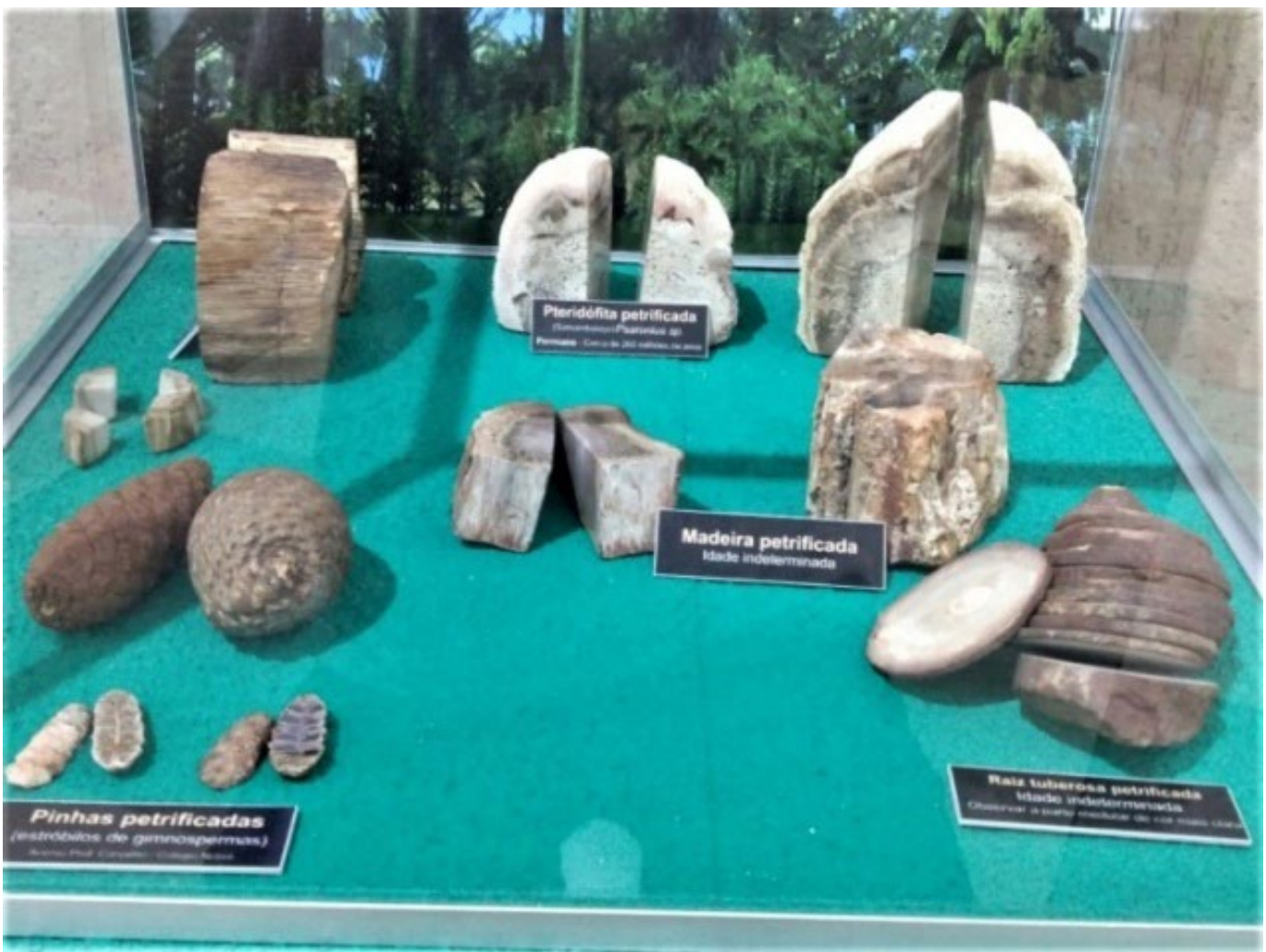

Fonte: Autores (2019).

A face externa do folder, por sua vez, apresenta um breve texto e imagens relacionados aos vertebrados terrestres, anfíbios (período Permiano) e répteis que viveram antes do surgimento dos dinossauros (período Triássico). Dentre estes, há exemplares de répteis semelhantes a mamíferos (dicinodontes e cinodontes, sendo este último ancestral dos mamíferos) e uma espécie de arcossauro primitivo anterior aos dinossauros (Figura 3). 
Figura 3: Vertebrados terrestres: (a) crânio do anfíbio extinto Australerpeton cosgriffi proveniente da Serra do Cadeado (PR), da Formação Rio do Rasto; (b) crânio de Dinodontosaurus turpior, dicinodonte proveniente do Geoparque da Paleorrota (RS); (c) crânio de Massetognathus, cinodonte herbívoro proveniente da região de Candelária (RS); (d) crânio de Karamuruvorax, arcossauro carnívoro da Formação Santa Maria (RS)
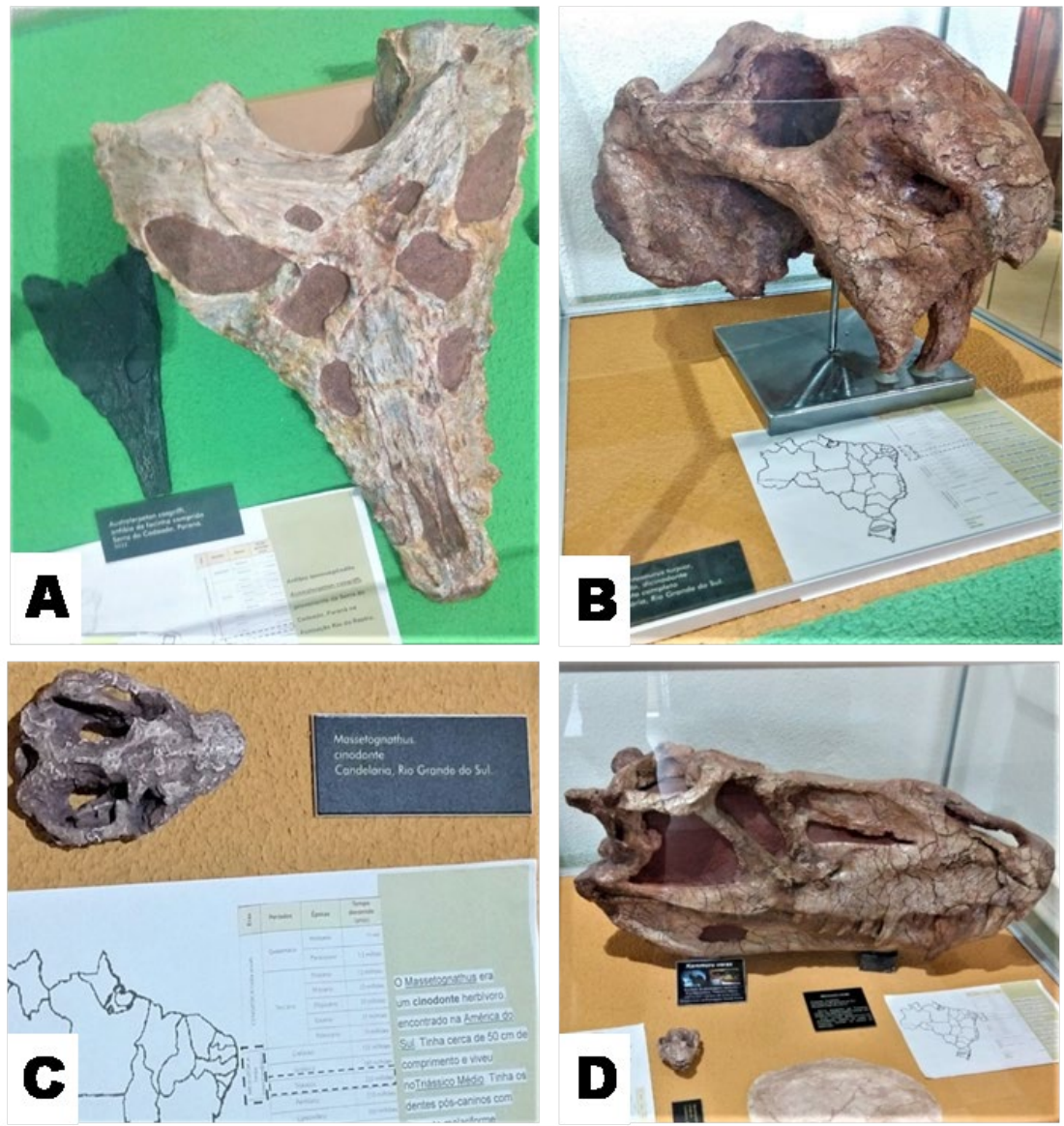

Fonte: Autores (2019).

O folder traz na capa (Figura 4), também na face externa, uma homenagem ao paleoartista regional Luciano Vidal com uma ilustração sua de um Caiuajara dobruskii, uma espécie inédita de pterossauro encontrada no noroeste do Paraná, região onde se localiza o MUDI (MANZIG et al., 2014). Segundo Martins, Gouvêa e Piccinini (2005), imagens são importantes recursos para a comunicação de ideias científicas e são mais facilmente entendidas quando acompanhadas de pequenos textos explicativos e outros estímulos. Este material instrucional foi elaborado e ricamente 
ilustrado com fotos dos fósseis associadas a pequenos textos explicativos, que, juntos, se configuram em ferramentas essenciais para os leitores compreenderem de forma mais eficaz o conteúdo. Constituindo, assim, o processo não formal de aprendizagem.

Por fim, após várias revisões, a versão final do folder foi impressa e em breve começará a ser distribuída durante as visitas guiadas ao setor de Paleontologia do museu, realizando, dessa forma, como proposto, um trabalho possivelmente ainda mais eficiente na Educação não formal.

Figura 4: Folder na versão final (face interna e externa). Material em formato de folder de duas dobras, em tamanho A4 e com orientação horizontal.
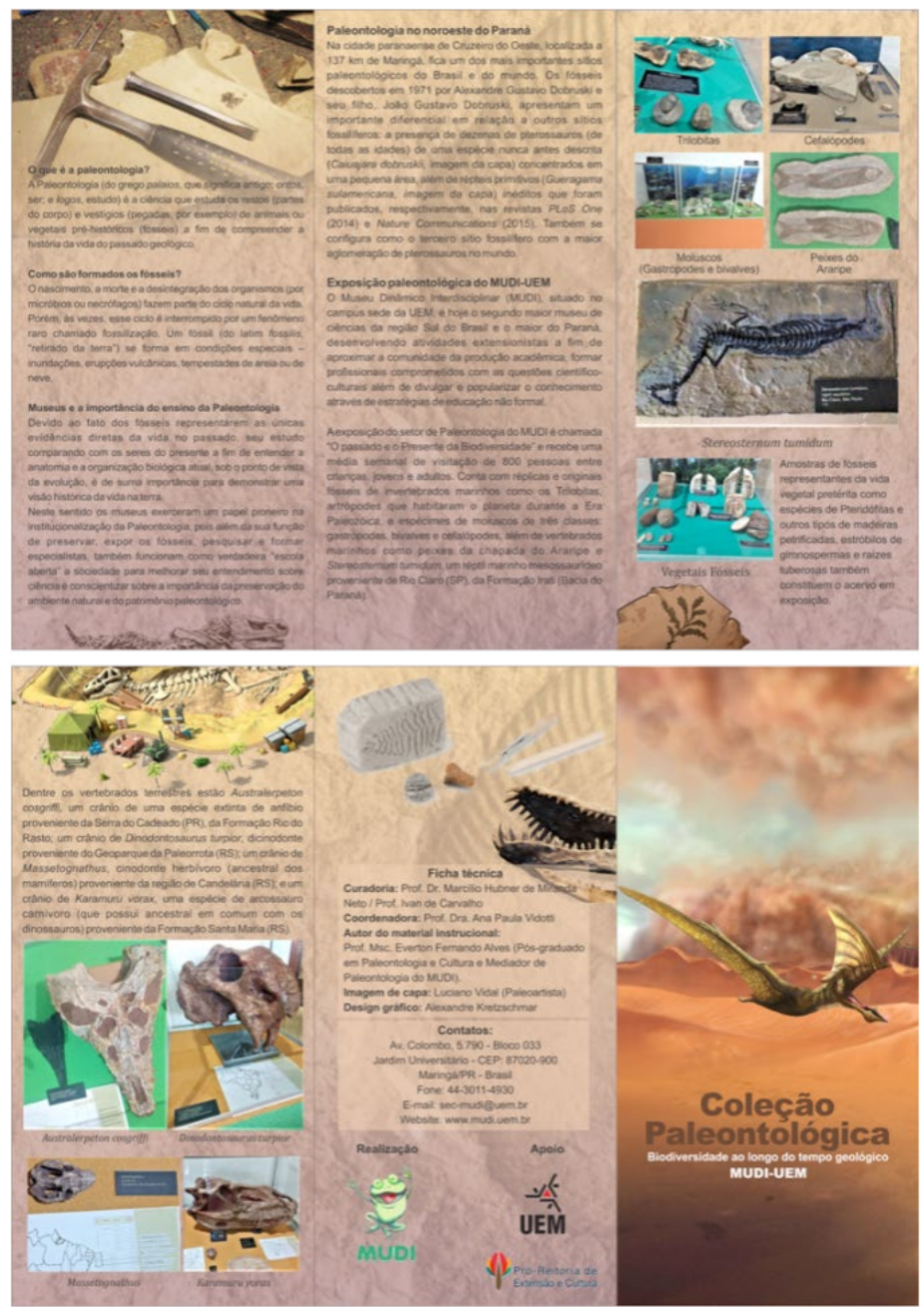

Fonte: Autores (2019). 


\section{Considerações Finais}

Poucos materiais instrucionais na forma de folder têm incorporado, em linguagem popular, informações a respeito de pesquisas científicas contemporâneas, especialmente aquelas de importância regional. Acredita-se que, da forma como o folder foi desenvolvido, sua utilização como ferramenta de educação aumentará a conscientização acerca da importância da Paleontologia, sua ocorrência na região e o consequente geoturismo urbano. De igual modo, se distribuído em palestras e cursos de treinamento para os mediadores do setor de Paleontologia do museu, permitirá que estes desenvolvam ainda mais o conteúdo paleontológico nas visitas guiadas de escolas e público em geral.

Poderá servir também como material didático para professores e profissionais da área de educação, agregando conhecimento para a divulgação científica durante o processo de ensino-aprendizagem. Esta experiência de desenvolvimento e distribuição de folders com maior interação com a sociedade possibilitará, inclusive, que a difusão do conhecimento científico proposta pelo museu e seu setor de Paleontologia, foco deste trabalho, sejam potencializados e atinjam cada vez mais um número maior de pessoas.

\section{Development of instructional material (folder) for Non- formal Education of Paleontology in a Museum of Sciences from Southern Brazil}

\section{Abstract}

The development of printed instructional material to be made available in the museum environment can not be understood outside the context of scientific education. Thus, this study aimed to describe the process of building a folder and its main characteristics for the diffusion of paleontological knowledge and the expansion of the scientific literacy potential of the Museu Dinâmico Interdisciplinar of the Universidade Estadual de Maringá (MUDI/UEM). Action research was used as a research method, and it was developed in four stages: content choice, based on the needs of the target audience; choice of illustrations; photographs of the main fossil samples of the collection; and content preparation, based on scientific literature. It is believed that, as the folder was developed, its use as educational tool will increase awareness about the importance of Paleontology, its occurrence in the region and the consequent urban geotourism.

Keywords: Scientific dissemination. Courseware. Educational Resources. 


\section{Referências}

BERGQVIST, L. P.; PRESTES, S. B. S. Kit paleontológico: um material didático com abordagem investigativa. Ciência \& Educação (Bauru),v. 20, n. 2, p. 345-357, 2014.

CADAVEZ, C. "Mas que mundo é este?", ou de como tem de ser diferente a divulgação das práticas de fruição cultural para os turistas millennial - um estudo de caso pensando nos museus. Revista Iberoamericana de Turismo - RITUR, v. 7, n. 3, p. 215-228, 2017.

DE PAULA, M. A. N. R.; CARVALHO, A. P. O gênero textual folder a serviço da educação ambiental. REGET, v. 18, n. 2, p. 982-989, 2014.

INDALÉCIO, A. B.; RIBEIRO, M. G. M. Gerações Z e Alfa: os novos desafios para a educação contemporânea. Revista Unifev: Ciência e Tecnologia, v. 2, n. 2, p. 137-148, 2016.

KARWOSKI, A. M. Estratégias de leitura de fôlderes. Estudos Linguísticos, v. 34, p. 698-701, 2005.

KELlNER, A. W. A. Museus e a Divulgação Científica no Campo da Paleontologia. Anuário do Instituto de Geociências - UFRJ, v. 28, n. 1, p. 116-130, 2005.

LEAL, M. D. As práticas envolvendo Paleontologia como estratégias pedagógicas em museus de ciências. In: X Congresso Nacional de Educação - Educere, 2011, Curitiba. X Congresso Nacional de Educação - Educere, 2011. Curitiba: Pontifícia Universidade Católica do Paraná, 2011. v. 11.

MANZIG, P. C. et al. Discovery of a Rare Pterosaur Bone Bed in a Cretaceous Desert with Insights on Ontogeny and Behavior of Flying Reptiles. PLoS One, v. 9, n. 8, p. e100005, 2014.

MARTINS, I.; GOUVÊA, G.; PICCININI, C. Aprendendo com imagens. Ciência e Cultura, v. 57, n. 4, p. 38-40, 2005.

OELOFSEN, B. W.; ARAÚJO, D. C. Mesosaurus tenuidens and Stereosternum tumidum from the Permian Gondwana of both Southern Africa and South America. South African Journal of Science, v. 83, n. 6, p. 370-72, 1987.

PEDRANCINI, V. D. et al. Ensino e aprendizagem de biologia no ensino médio e a apropriação do saber científico e biotecnológico. Revista Electrónica de Enseñanza de lãs Ciencias, v. 6, n. 2, p. 299-309, 2007.

RODRIGUES, M. A. N. Estratégias de leitura aplicadas ao gênero folder. \# Tear: Revista de Educação Ciência e Tecnologia, v.3, n.2, p. 1-12, 2014.

SANTOS, W. F. S.; CARVALHO, I. S.; RIBEIRO, L. C. B. Diagnóstico para o turismo paleontológico em Peirópolis - Uberaba (Minas Gerais): A importância do Museu dos Dinossauros no desenvolvimento socioespacial local. In: Congresso Brasileiro DE Geologia, 43, Aracaju, 2006. Anais, Salvador, Talismã, p. 202.

THIOLLENT, M. Metodologia da pesquisa-ação. 14. ed. São Paulo: Cortez, 2005.

VERONESE, R. Histórico das exposições de paleontologia do Museu Nacional: um espaço de educação não formal. Rio de Janeiro, 2011, 60 f. Trabalho de conclusão de curso (Licenciatura em Ciências Biológicas) - Universidade Federal do Rio de Janeiro, Rio de Janeiro, 2011.

VIEIRA, A. C. M. A Contribuição dos Museus para a Institucionalização e Difusão da Paleontologia. Anuário do Instituto de Geociências - UFRJ, v. 30, n. 1, p. 158-167, 2007. 